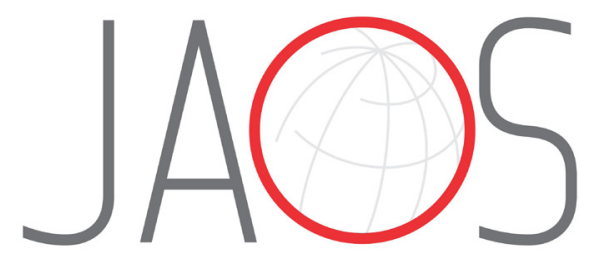
JOURNAL OF APPLIED ORAL SCIENCE

\title{
Influence of Helicobacter pylori culture supernatant on the ecological balance of a dual-species oral biofilm
}

\section{Abstract}

Wenling ZHANG ${ }^{1}$

Xiaohong DENG ${ }^{1}$

Xuedong $\mathrm{ZHOU}^{1}$

Yuqing $\mathrm{HAO}^{1}$

Yuqing LI ${ }^{1}$
Submitted: March 10, 2017 Modification: June 22, 2017

Accepted: July $1^{\text {st }}, 2017$

Corresponding address: Yuqing Li

State Key Laboratory of Oral Diseases - West China. School of Stomatology - Sichuan University, No. 14 - Section 3 - Renmin Road South - Chengdu. 610041 - People's Republic of China. Phone: 86-28-85501232 - Fax: 86-28-85582167 e-mail: liyuqing@scu.edu.cn
Dental caries is a chronic progressive disease occurring in the tooth hard tissue due to multiple factors, in which bacteria are the initial cause. Both Streptococcus mutans and Streptococcus sanguinis are main members of oral biofilm. Helicobacter pylori may also be detected in dental plaque, playing an important role in the development of dental caries. Objective: The aim of this study was to investigate the effect of $H$. pylori culture supernatant on S. mutans and $S$. sanguinis dual-species biofilm and to evaluate its potential ability on affecting dental health. Material and methods: The effect of $H$. pylori supernatant on single-species and dual-species biofilm was measured by colony forming units counting and fluorescence in situ hybridization (FISH) assay, respectively. The effect of $H$. pylori supernatant on $S$. mutans and $S$. sanguinis extracellular polysaccharides (EPS) production was measured by both confocal laser scanning microscopy observation and anthrone-sulfuric acid method. The effect of $H$. pylori supernatant on $S$. mutans gene expression was measured by quantitative real-time PCR (qRT-PCR) assays. Results: $H$. pylori supernatant could inhibit both $S$. mutans and $S$. sanguinis biofilm formation and EPS production. S. sanguinis inhibition rate was significantly higher than that of $S$. mutans. Finally, S. mutans bacteriocin and acidogenicity related genes expression were affected by $H$. pylori culture supernatant. Conclusion: Our results showed that $H$. pylori could destroy the balance between $S$. mutans and $S$. sanguinis in oral biofilm, creating an advantageous environment for $S$. mutans, which became the dominant bacteria, promoting the formation and development of dental caries.

Keywords: Helicobacter pylori. Streptococcus mutans. Streptococcus sanguinis. Oral biofilm. Ecological balance.

'State Key Laboratory of Oral Diseases, National Clinical Research Center for Oral Diseases, West China Hospital of Stomatology, Sichuan University, Chengdu, People's Republic of China. 


\section{Introduction}

Helicobacter pylori is implicated in several diseases such as gastritis, gastric ulcers and gastric carcinoma ${ }^{20,26}$. Approximately $10 \%$ of individuals suffer from gastritis or gastric ulcer due to $H$. pylori infection ${ }^{28}$. $H$. pylori can also be detected in saliva, on the dorsum of the tongue, on the surface of oral ulceration and in dental plaque $8,15,22$, the latter representing a crucial location, playing an important role in the development of dental caries. The prevalence of $H$. pylori infection in the oral cavity of gastric $H$. pylori-positive people is significantly higher than that of gastric $H$. pylorinegative people ${ }^{30}$. Researchers increasingly consider $H$. pylori as a conditional pathogen that exists in the oral cavity of both healthy people and patients with gastritis ${ }^{14}$. H. pylori infection in the oral cavity is associated with dental caries and poor oral hygiene. The caries rate in $H$. pylori-positive people is higher than that in $H$. pylori-negative people ${ }^{14}$.

According to the World Health Organization (WHO), dental caries has been one of the most important global oral health issues, accounting for $60-90 \%$ school-aged children of most of the industrialized countries ${ }^{27}$. Streptococcus mutans is considered a crucial agent in caries pathogenesis because of its cariogenic traits $^{9,23}$. Glucans are essential to the adhesion of S. mutans to the tooth surface and to other oral bacteria, as well as to the formation of dental biofilms matrix ${ }^{11,29}$. Furthermore, S. mutans possesses aciduric properties, allowing it to perform glycolysis at low $\mathrm{pH}$ values within the matrix of the biofilm, which result in dental enamel demineralization ${ }^{24}$. Streptococcus sanguinis is usually colonizing oral biofilm ${ }^{12}$, having been considered a "good" member in the oral biofilm, since its presence is associated with the absence of caries $^{13}$. S. mutans and S. sanguinis inversely affect each other in the formation of dental plaque ${ }^{13,21}$. Previous studies have shown that the interspecies interaction between $S$. mutans and $S$. sanguinis is mediated by $S$. mutans acidogenicity (production of lactic acid by L-lactate dehydrogenase, encoded by ldh) and production of bacteriocin (two major mutacins, mutacin IV and mutacin $\mathrm{V}$, encoded by $n \operatorname{lm} A B$ and $n / m C$, respectively) ${ }^{13}$. These two streptococci compete for teeth colonization, since elevated levels of $S$. sanguinis in the early colonization results in a delayed colonization by $S$. mutans. Conversely, S. mutans teeth colonization is associated with low levels of
S. sanguinis ${ }^{13}$. Indeed, caries-free children have high levels of $S$. sanguinis in their saliva and dental plaque compared to children with carious lesions who, instead, showed an elevated concentration of $S$. mutans ${ }^{7}$. Therefore, the imbalanced microecology of dental plaque was considered a key factor leading to caries. Currently, several studies ${ }^{10,14,15,25}$ are available to demonstrate the relationship between oral $H$. pylori and dental caries, although the mechanism is still unclear. In this study we analyzed the effects of $H$. pylori culture supernatant on S. mutans and $S$. sanguinis dual-species biofilm formation.

\section{Material and methods}

\section{Bacterial strains and growth conditions}

H. pylori ATCC 43504 was incubated in brain heart infusion (BHI) fluid medium with $5 \%$ Fetal Bovine Serum (FBS) that represented the $H$. pylori medium, in a microaerophilic chamber $\left(6 \% \mathrm{O}_{2}, 10 \% \mathrm{CO}_{2}\right.$, and $84 \% \mathrm{~N}_{2}$; Thermo Fisher Scientific, Inc., Waltham, MA, USA). S. mutans UA159 (ATCC 700610) and S. sanguinis (ATCC 10556) were maintained in BHI fluid medium in an anaerobic chamber $\left(10 \% \mathrm{H}_{2}, 5 \% \mathrm{CO}_{2}\right.$, and $85 \% \mathrm{~N}_{2}$; Thermo Fisher Scientific, Inc., Waltham, MA, USA) for planktonic growth. Both S. mutans and $S$. sanguinis were grown in $\mathrm{BHI}$ with $1 \%\left(\mathrm{w} / \mathrm{v}^{-1}\right)$ sucrose as a supplemental carbohydrate source, to allow biofilm formation. Biofilms were incubated at $37^{\circ} \mathrm{C}$ without agitation.

\section{H. pylori supernatant collection}

$H$. pylori stored at $-80^{\circ} \mathrm{C}$ was incubated in $\mathrm{BHI}$ fluid medium with $5 \%$ FBS in the mentioned microaerophilic environment to allow their recovery, and subsequently subcultured for four days. The bacterial solution was centrifuged at $4000 \mathrm{~g} \cdot \mathrm{min}^{-1}$ for $10 \mathrm{~min}$; the supernatant was collected and subsequently filtered by a $0.22 \mu \mathrm{m}$ filter under aseptic conditions. The supernatant, named $H$. pylori supernatant, was stored at $-20^{\circ} \mathrm{C}$ until use.

\section{Planktonic growth assay}

S. mutans and $S$. sanguinis overnight bacterial cultures were diluted to an $\mathrm{OD}_{600 \mathrm{~nm}}=0.2$ (according to McFarland turbidity standards) in $\mathrm{BHI}$ and placed in a sterile 96-well microtiter plate to perform planktonic growth curve assay. Each well containing $190 \mu \mathrm{L} S$. 
mutans or $S$. sanguinis culture $\left(\mathrm{OD}_{600 \mathrm{~nm}}=0.2\right)$ plus 10 $\mu \mathrm{L} H$. pylori supernatant represented the experimental group, while the control group was represented by the same $190 \mu \mathrm{L}$ bacteria culture plus $10 \mu \mathrm{L} \mathrm{H}$. pylori medium. Plates were incubated at $37^{\circ} \mathrm{C}$ and sampled at hourly intervals for $24 \mathrm{~h}$. The optical density at $600 \mathrm{~nm}$ (OD600, transmittance) was recorded hourly using a microplate reader (BioTek, Winooski, VT, USA) as previously described ${ }^{19}$. Four replicates of each bacterium for each group were used.

\section{Fluorescence in situ hybridization (FISH)}

Overnight bacterial cultures of S. mutans and S. sanguinis were adjusted to $\mathrm{OD}_{600 \mathrm{~nm}}=0.2$ in fresh $\mathrm{BHI}$ supplemented with $1 \%$ sucrose. Cultures of each bacterial species were inoculated either sequentially at a $3 \mathrm{~h}$ interval or simultaneously on saliva-coated glass coverslips in a 24 -well cell culture plate. The experimental groups contain $1.5 \mathrm{~mL}$ BHI with $1 \%$ $\left(\mathrm{w} / \mathrm{v}^{-1}\right)$ sucrose, $200 \mu \mathrm{L}$ S. mutans culture, $200 \mu \mathrm{L} \mathrm{S}$. sanguinis culture and $100 \mu \mathrm{L} H$. pylori supernatant, while the control groups had $100 \mu \mathrm{L} \mathrm{H}$. pylori medium (BHI with 5\% FBS) instead of $H$. pylori supernatant. Finally, standard 24-well cell culture plates were incubated at $37^{\circ} \mathrm{C}$ under anaerobic condition for $24 \mathrm{~h}$.

After the 24-h incubation period, biofilms were fixed in $4 \%$ paraformaldehyde, labeled with oligonucleotide probes (Probe 5'-ACTCCAGACTTTCCTGAC-3' specific for S. mutans was labeled with FITC and probe 5'-GCATACTATGGTTAAGCCACAGCC-3' specific for $S$. sanguinis was labeled with $\mathrm{ROX}$ ) and analyzed by species-specific FISH as previously described ${ }^{3}$. Micrographs from at least five randomly selected fields of each sample were captured. S. mutans to S. sanguinis ratio was calculated based on the coverage area of each species as determined by IMAGE PRO PLUS 6.0 analysis (Media Cybernetics, Silver Spring, MD, USA).

\section{Biofilm single colony forming units (CFU) count}

Standard 24-well cell culture plates were filled with $200 \mu \mathrm{L}$ S. mutans or S. sanguinis culture $\left(\mathrm{OD}_{600 \mathrm{~nm}}=0.2\right)$ and $H$. pylori supernatant in $\mathrm{BHI}$ to a final amount of $2 \mathrm{~mL}$ containing $1 \%\left(\mathrm{w} / \mathrm{v}^{-1}\right)$ sucrose in total. The control group had the same composition except the $5 \% \mathrm{H}$. pylori medium that replaced the $5 \% \mathrm{H}$. pylori supernatant. Plates were incubated at $37^{\circ} \mathrm{C}$ under anaerobic conditions for $24 \mathrm{~h}$. Plates were washed twice with sterile PBS to remove planktonic and loosely adherent cells. Adherent cells from the biofilm were resuspended by vigorous pipetting and vortexing and were serially diluted $10^{6}$-fold through $10^{8}$-fold and plated onto $\mathrm{BHI}$ agar plates. Each group was performed in triplicate. Finally, plates were incubated at $37^{\circ} \mathrm{C}$ under anaerobic conditions for $48 \mathrm{~h}$. Colony forming units (CFU) were quantified to evaluate the $H$. pylori supernatant inhibition ratio.

\section{Confocal laser scanning microscopy}

Sterilized coverslips (1 cm in diameter) were placed into each well of standard 24-well cell culture plates to allow biofilms development. The standard 24-well cell culture plates contained $200 \mu \mathrm{L}$ S. mutans or $S$. sanguinis culture $\left(\mathrm{OD}_{600 \mathrm{~nm}}=0.2\right)$ and H. pylori supernatant in BHI to a final amount of $2 \mathrm{~mL}$ containing $1 \%\left(\mathrm{w} / \mathrm{v}^{-1}\right)$ sucrose in total. Alexa Fluor 647 (10 000 MW; Molecular Probes, Invitrogen, Carlsbad, CA, USA) was added to each well to label the formed extracellular polysaccharides (EPS) as previously described ${ }^{3}$. The control group had the same composition except that $5 \% \mathrm{H}$. pylori supernatant was replaced by $5 \% \mathrm{H}$. pylori medium.

The plate was incubated at $37^{\circ} \mathrm{C}$ under anaerobic conditions for $24 \mathrm{~h}$. Next, we removed the planktonic bacteria, washed the coverslips with sterile PBS and dried them with a sterile filter paper, keeping them in the dark for the entire procedure. Bacteria were stained with SYTO 9 (Molecular Probes, Invitrogen, Carlsbad, CA, USA) as previously reported ${ }^{3}$ and coverslips were washed using deionized sterile water to remove the residual dye, dried with a sterile filter paper, and sealed with immersion oil type- $F$ for laser scanning confocal microscopy (Leica TCS SP2; Leica Microsystems, Wetzlar, Germany) provided with a $63 \times$ oil immersion objective lens. Image collection gates were set at 655 to $690 \mathrm{~nm}$ for Alexa Fluor 647 and at 495 to $515 \mathrm{~nm}$ for SYTO 9. During imaging, amplifier gain (1.0), detector gain (500 V), and offset (0\%) were kept constant. Five randomly selected fields were scanned for each sample. The quantification of EPS/bacteria biomass was performed with IMARIS 7.0.0 (Bitplane, Zurich, Switzerland), as previously described $^{19}$.

\section{Anthrone-sulfuric acid method to determine biofilm insoluble EPS production}

Standard 24-well cell culture plates contained 200 $\mu \mathrm{L} S$. mutans or $S$. sanguinis culture $\left(\mathrm{OD}_{600 \mathrm{~nm}}=0.2\right)$ and $H$. pylori supernatant in BHI to a final amount of $2 \mathrm{~mL}$ containing $1 \%\left(\mathrm{w} / \mathrm{v}^{-1}\right)$ sucrose in total. The 


\begin{tabular}{|l|l|}
\hline \multicolumn{1}{|c|}{ Primer Name } & \multicolumn{1}{c|}{ Sequence (5' to $\mathbf{3}^{\prime}$ ) } \\
\hline nlmA-Fwd & AAAATAAATTGTTATACTAAAGATGTTGGTTG \\
\hline nlmA-Rev & TATTTTGTCTTAAACGGTCATTTTTGA \\
\hline nlmC-Fwd & CCACAGGAATTAAGAGCTCCTCCGATT \\
\hline nlmC-Rev & GCGGATGGAATTGTGCAGCAGGTA \\
\hline Idh-Fwd & GGCGACGCTCTTGATCTTAG \\
\hline Idh-Rev & GGTTAGCAGCAACGAGGAAG \\
\hline 16S rRNA-Fwd & AGCGTTGTCCGGATTTATTG \\
\hline $16 S$ rRNA-Rev & CTACGCATTTCACCGCTACA \\
\hline
\end{tabular}

Figure 1- Primers used for qRT-PCR assays in this study

control group had the same composition except that $5 \% \mathrm{H}$. pylori supernatant was replaced by $5 \%$ H. pylori medium. The plate was incubated at $37^{\circ} \mathrm{C}$ under anaerobic conditions for $24 \mathrm{~h}$. Next, planktonic bacteria were removed and the adherent biofilm was resuspended in $2 \mathrm{~mL}$ PBS. The detailed procedure was performed as previously described ${ }^{19}$. Waterinsoluble extracellular polysaccharides were extracted from the sample using $1.0 \mathrm{M} \mathrm{NaOH}$ with agitation for $2 \mathrm{~h}$ at $37^{\circ} \mathrm{C}^{19}$. The concentration of alkali-soluble carbohydrate was determined in the supernatant using the anthrone-sulfuric method. Briefly, the alkalisoluble carbohydrate solution was mixed with three volumes of anthrone-sulfuric acid reagent and heated in a water bath at $95^{\circ} \mathrm{C}$ for 5 min until the reaction was complete ${ }^{19}$. Then, the solution was allowed to cool-down to room temperature, and its absorbance was measured in a 96-well cell culture plate at 625 nm using a microplate reader (BioTek).

\section{Quantitative real-time PCR (qRT-PCR)}

Gene-specific primers for $n \operatorname{lm} A, n \operatorname{lmC}$, and $/ d h$ were designed, as shown in Figure 1 . Total bacterial RNA was isolated, purified, cDNA was reverse transcribed, and PCR reactions were performed as previously described 6 . Different gene expressions were normalized to $16 \mathrm{~S}$ rRNA gene levels. Data were analyzed according to the $2^{-\Delta \Delta C T}$ method $^{3}$.

\section{Data analysis and statistics}

In this study, all of the in vitro experiments include biological and technical triplicates. Exploratory data analysis was performed to determine the most appropriate statistical tests. Assumptions of equal variances and normal distribution of errors were also checked. Data were further analyzed using SPSS 16.0 (SPSS, Inc, Chicago, IL, USA), and unpaired Student's $t$-test was used to compare data of two groups. Results are calculated as average values \pm SD (standard deviation). Data were considered significantly different if the two-tailed $P$-value was $<0.05$.

\section{Results}

Effect of $H$. pylori culture supernatant on $S$. mutans or $S$. sanguinis single-species biofilm formation

In the single-species biofilm formation, S. mutans and $S$. sanguinis CFU levels showed a statistically significant reduction due to the presence of $H$. pylori supernatant and not to $H$. pylori medium. Indeed, $S$. mutans CFU levels were $222 \times 10^{7} \mathrm{CFU} / \mathrm{mL}$ and $169 \times 10^{7}$ $\mathrm{CFU} / \mathrm{mL}$ in the presence of $H$. pylori medium and $H$. pylori supernatant respectively, whereas $S$. sanguinis CFU levels were $230 \times 10^{7} \mathrm{CFU} / \mathrm{mL}$ and $25 \times 10^{7} \mathrm{CFU} / \mathrm{mL}$, respectively. The inhibition rate exerted on $S$. sanguinis by $H$. pylori supernatant was statistically significantly higher than that exerted on $S$. mutans (Figure 2A) $\left(F_{(3,20)}=1.576 ; R^{2}=0.9935 ; P<0.05\right)$. The inhibition of $S$. sanguinis and $S$. mutans by $H$. pylori supernatant was also confirmed by crystal violet dye staining of single-species biofilm (Figure 2B) $\left(F_{(3,20)}=0.9551\right.$; $\left.\mathrm{R}^{2}=0.9779 ; P<0.05\right)$.

\section{Effect of H. pylori culture supernatant on dual- species biofilm}

Since $H$. pylori could be detected in dental plaque and is related to the presence of dental caries, we examined the effect of $H$. pylori culture supernatant on the ecological balance of a dual-species biofilm composed by $S$. mutans and $S$. sanguinis. The 24-h dual-species bacteria biofilm formation results showed that the $S$. mutans/S. sanguinis ratio in the experimental groups treated with $H$. pylori supernatant was higher than that in the control group treated with H. pylori medium (Figures $3 \mathrm{~A}$ and $3 \mathrm{~B})\left(\mathrm{F}_{(5,30)}=0.5442\right.$; 
$\left.\mathrm{R}^{2}=0.9959 ; P<0.05\right)$. The $S$. mutans $/ S$. sanguinis ratio was highest in the group in which $S$. mutans was incubated $3 \mathrm{~h}$ earlier than $\mathrm{S}$. sanguinis, while the lowest ratio was in the group in which $S$. sanguinis was incubated $3 \mathrm{~h}$ earlier than $S$. mutans $\left(\mathrm{F}_{(5,30)}=0.5442\right.$; $\left.\mathrm{R}^{2}=0.9959 ; P<0.05\right)$. In other words, the microbial colonization was dominated by $S$. mutans in the groups treated with $H$. pylori supernatant.
Effect of $H$. pylori culture supernatant on $S$. mutans or $S$. sanguinis EPS production

We found, as expected, a decrease in both the biofilm and the EPS after $H$. pylori supernatant treatment if compared with the biofilm after $H$. pylori medium treatment. In addition, $H$. pylori supernatant inhibited EPS production in both bacteria, although the inhibiting effect on $S$. sanguinis was statistically significantly stronger than that on S. mutans (Figures $4 \mathrm{~A}$ and $4 \mathrm{~B})(P<0.05)$. The Results of the anthrone-

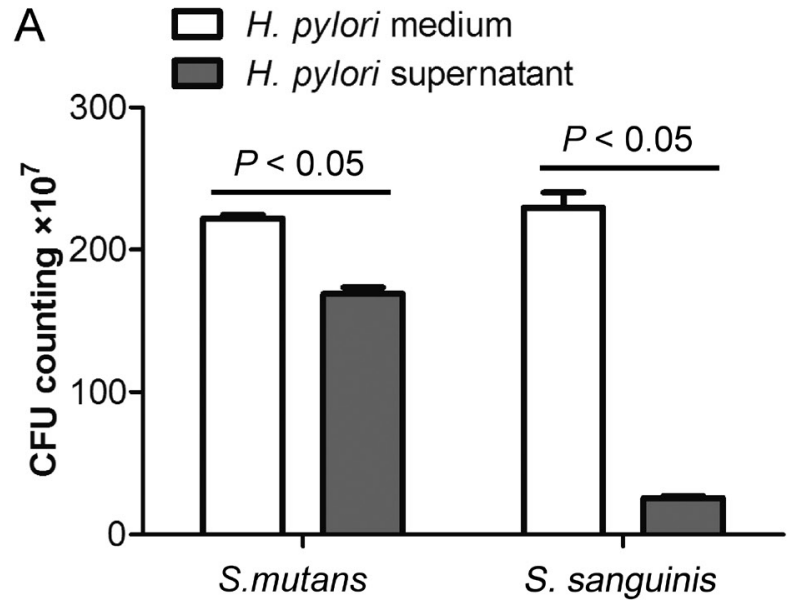

B

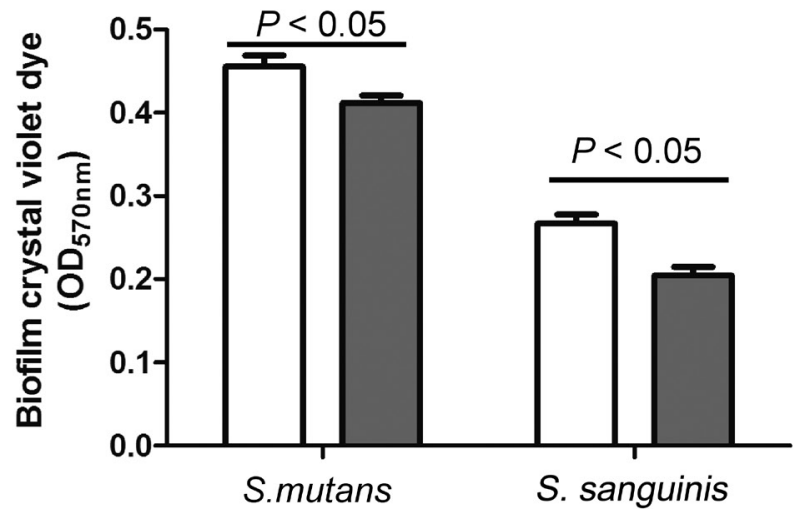

Figure 2- Effect of $H$. pylori supernatant on S. mutans and S. sanguinis biofilm formation. Planktonic bacteria were removed from $S$. mutans or $S$. sanguinis culture and the adherent biofilm was resuspended and diluted. A quantity of $100 \mu \mathrm{L}$ of the final bacterial solution was placed onto the $\mathrm{BHI}$ agar plate. Colony forming units (CFU) were quantified to evaluate $H$. pylori supernatant inhibition ratio. Each group was performed in triplicate. Data were considered significantly different if the two-tailed $\mathrm{P}$-value was $<0.05$.

(A) Effect of $H$. pylori supernatant and $H$. pylori medium on single-species biofilm measured by CFU counting.

(B) Effect of $H$. pylori supernatant and $H$. pylori medium on single-species biofilm measured by crystal violet dye staining

A
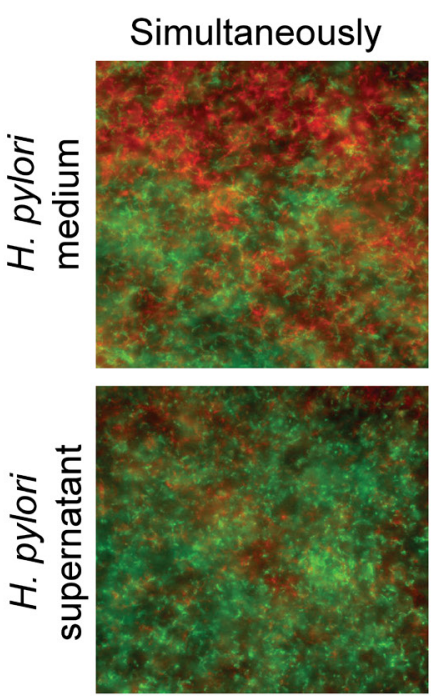

S. sanguinis

\section{S. mutans $3 \mathrm{~h}$ earlier $S$. sanguinis $3 \mathrm{~h}$ earlier}
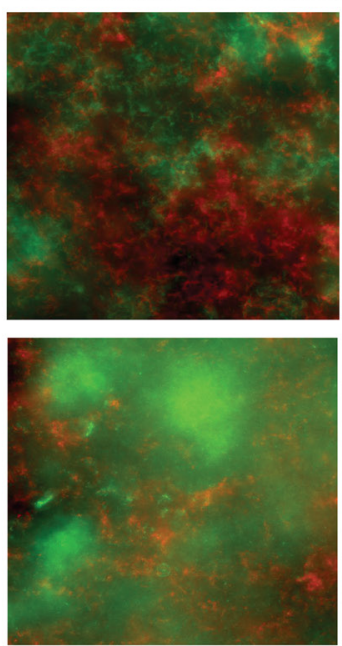
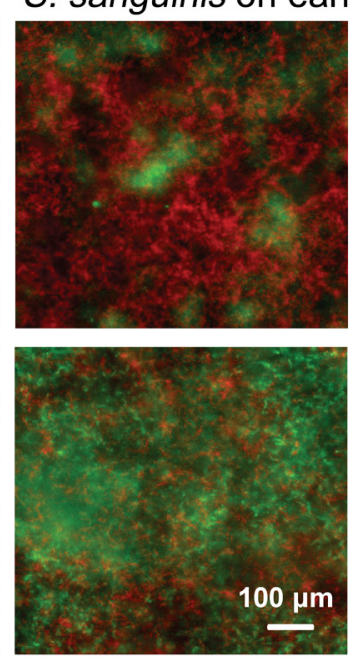

B

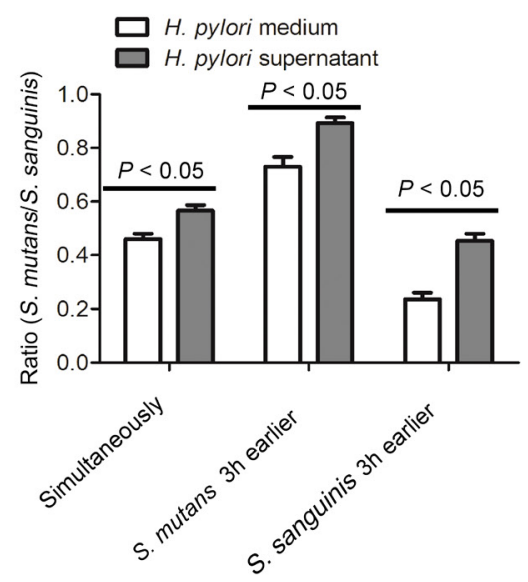

Figure 3- Effect of $H$. pylori supernatant on dual-species oral biofilm. Overnight bacterial cultures of $S$. mutans and $S$. sanguinis were inoculated either sequentially at a $3 \mathrm{~h}$ interval, or simultaneously on saliva-coated glass cover slips. After $24 \mathrm{~h}$ incubation, biofilms were fixed, labeled and analyzed by species-specific FISH assays as described in "Material and methods". Data were considered significantly different if the two-tailed P-value was $<0.05$.

(A) FISH images of dual-species biofilm were taken by confocal laser scanning microscopy (60x magnification). Green: S. mutans; Red: S. sanguinis.

(B) S. mutans to S. sanguinis ratio in dual-species biofilm. Results were averaged from five randomly selected fields of each sample and are expressed as mean \pm standard deviation 
A
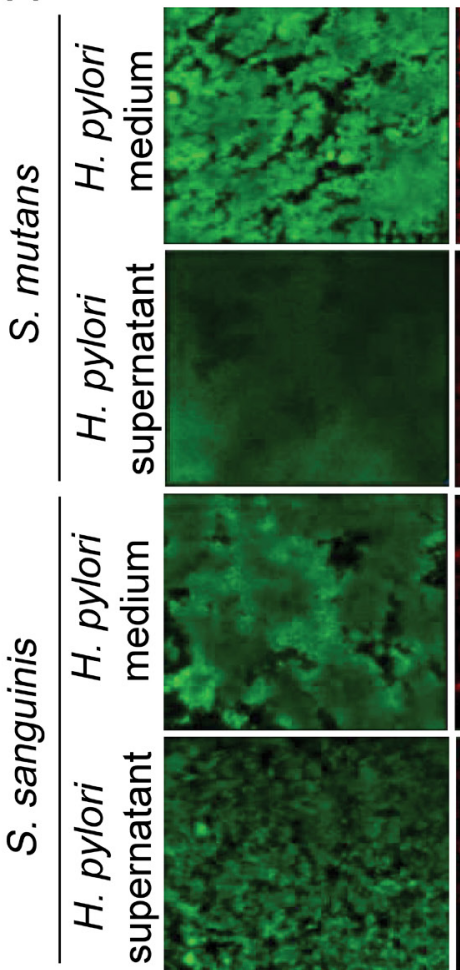

EPS
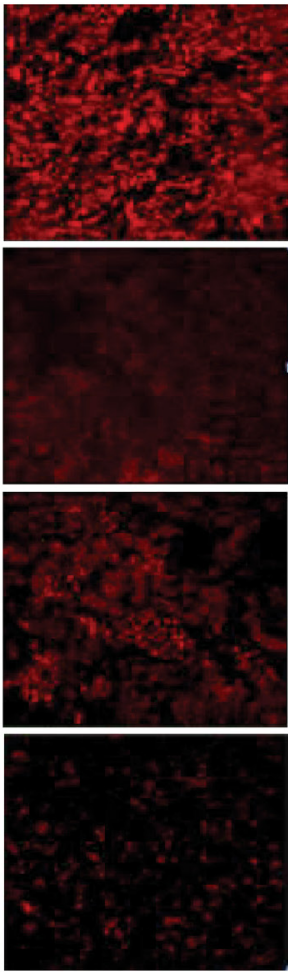

merged
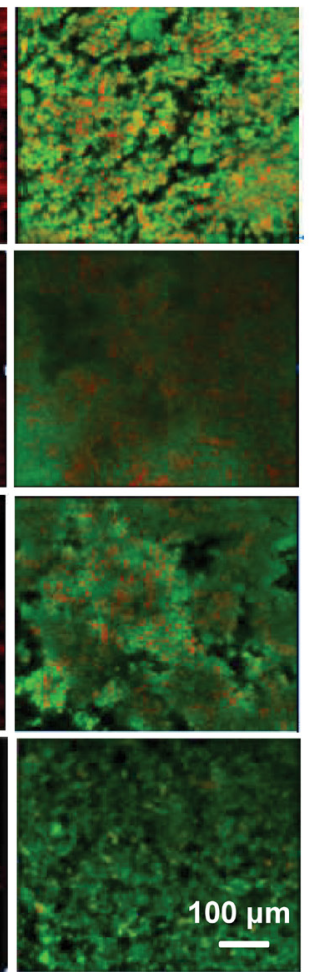

B
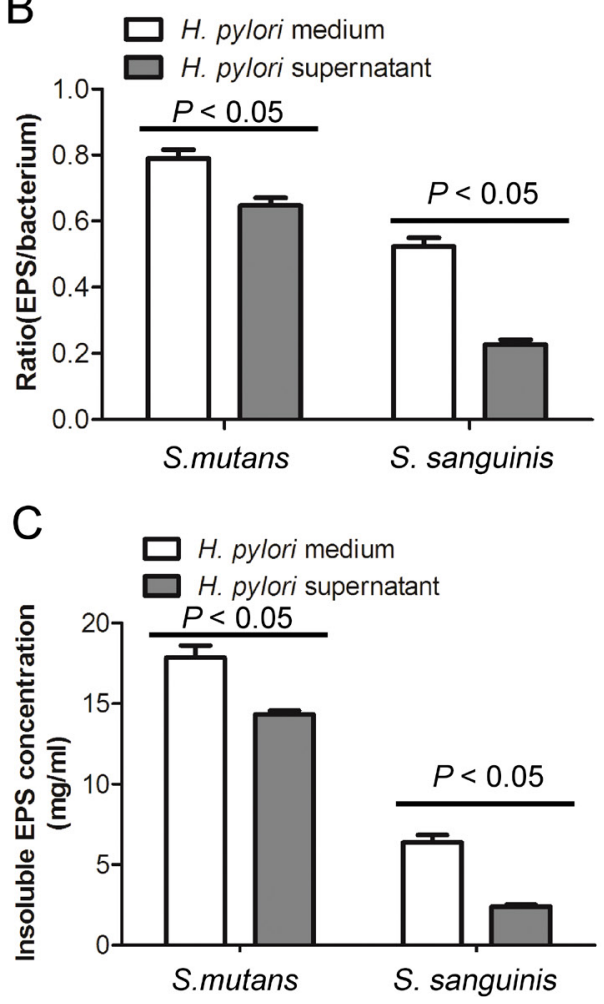

Figure 4- Effect of $H$. pylori supernatant on $S$. mutans and $S$. sanguinis biofilm and EPS. The effects of $H$. pylori supernatant on $S$. mutans and S. sanguinis biofilm and EPS were measured by both confocal laser scanning microscopy observation and anthranone sulfuric acid method as described in "Material and methods". Data were considered significantly different if the two-tailed P-value was <0.05.

(A) Confocal laser scanning microscopy images of single-species biofilms microscopy (60× magnifications). Live bacteria are green, EPS are red.

(B) EPS to bacterium ratio in single-species biofilm. Results were averaged from three randomly selected fields of each sample and are expressed as mean \pm standard deviation.

(C) Anthrone-sulfuric acid method to determine the biofilm insoluble EPS production treated with $H$. pylori supernatant and $H$. pylori medium

sulfuric acid method to determine the biofilm insoluble EPS showed that $H$. pylori supernatant could inhibit the production of biofilm insoluble EPS in both bacteria, and also in this experiment we found that the inhibition rate on $S$. sanguinis was statistically significantly higher than that on $S$. mutans (Figure 3C) $\left(F_{(3,20)}=1.968 ; R^{2}=0.9985 ; P<0.05\right)$. The results of anthrone-sulfuric acid method and confocal laser scanning microscopy techniques were consistent. Both experiments showed that $H$. pylori supernatant could inhibit the production of EPS in S. mutans and S. sanguinis biofilm.

Effect of $H$. pylori culture supernatant on $S$. mutans bacteriocin- and acidogenicity-related genes expression

Previous studies have shown that interspecies interaction between $S$. mutans and $S$. sanguinis is mediated by $S$. mutans acidogenicity and production of bacteriocin ${ }^{13}$. H. pylori supernatant was able to increase the percentage of $S$. mutans in a dual-species biofilm. Therefore, to validate whether S. mutans

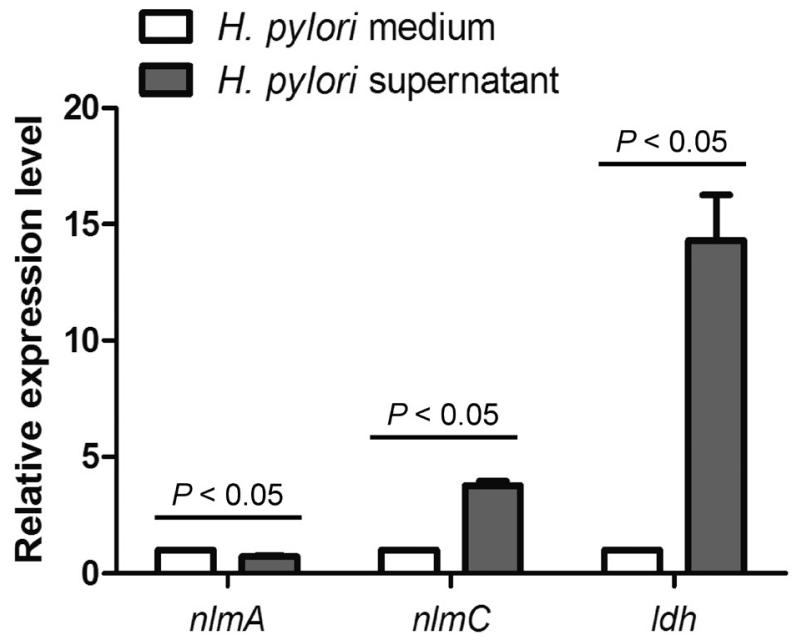

Figure 5- Effect of $H$. pylori supernatant on bacteriocin- and acidogenicity-related genes expression of $S$. mutans. qRTPCR assay was carried out as described in "Material and methods". All genes were amplified using specific primers. Different gene expressions were normalized to $16 \mathrm{~S}$ rRNA gene levels. Representative data are shown. Data were considered significantly different if the two-tailed $\mathrm{P}$-value was $<0.05$

bacteriocin- and acidogenicity-related gene expression was induced by $H$. pylori supernatant, we further investigated the expression of some $S$. mutans genes such as $n / m A$, encoding mutacin IV, $n \operatorname{lmC}$, encoding 
mutacin $\mathrm{V}$, and $/ d h$, encoding L-lactate dehydrogenase (Figure 5). Although the expression of $n / m A$ showed 0.7-fold change after the $H$. pylori supernatant treatment, Idh expression had a 3.8-fold increase, and $n / m C$ expression had a 14.3 -fold increase $(P<0.05)$.

\section{Discussion}

$H$. pylori is the first bacterium identified as a potential human carcinogenic pathogen ${ }^{18,26}$. It occurs in childhood by oral ingestion and persists for a lifetime in the host unless treated ${ }^{20}$. Several studies have demonstrated that $H$. pylori can be detected in dental plaque and saliva, making the oral cavity as the primary extra-gastric reservoir, which may be the source of infection and transmission ${ }^{4,10,30}$. The oral cavity is the starting point of the digestive tract, thus, because of the tight connection between oral cavity and digestive tract, the relationship between oral $H$. pylori and oral cavity diseases has caught increasing attention ${ }^{5}$. The association between $H$. pylori infection, dental caries and recurrent aphthous mouth ulcerations has been investigated in other researches ${ }^{6,25}$. A previous study showed that in $H$. pylori positive participants, caries prevalence rate was two times higher than in the participants without $H$. pylor $i^{14}$. Previous studies already have epidemiologic surveys regarding the relationship between dental caries and oral $H$. pylori, but the interaction between oral $H$. pylori and dental caries-related bacteria such as $S$. mutans and $S$. sanguinis has not been explored.

Oral biofilm can be defined as a diverse community of microorganisms, working as a system allowing bacterial adhesion and antibiotic resistance ${ }^{16}$. Oral biofilm is the key factor that causes dental caries, not bacterioplankton ${ }^{2,17}$. Thus, in this study we focused on oral biofilm to understand its role in caries formation. However, our attempts to culture $H$. pylori with other oral bacteria have failed because of the rigorous growth conditions needed by this bacterium ${ }^{1}$. Thus, in this study $H$. pylori supernatant was used to explore the influence of $H$. pylori on S. mutans and S. sanguinis biofilm. Our results showed that $H$. pylori supernatant could inhibit both $S$. mutans and $S$. sanguinis biofilm formation and EPS production. However, in a dualspecies biofilm model, $S$. mutans showed a superior competitive advantage over $S$. sanguinis under $H$. pylori supernatant treatment. The observations in gene expression assays suggested that $H$. pylori supernatant could induce the production of mutacin and enhance the acidogenicity of $S$. mutans, alluding the creation of an advantageous environment for $S$. mutans, which became the dominant bacteria. We also found that the production of EPS of $S$. mutans and $S$. sanguinis was inhibited by $H$. pylori supernatant. Thus, we hypothesized that $H$. pylori supernatant contained some specific substances that may be secreted effectors, small molecules or metabolites, and that these substances could inhibit streptococcal EPS synthesis, affecting, therefore, the biofilm formation. However, this hypothesis needs further studies to be confirmed.

We also found that $H$. pylori supernatant had no significant effect on planktonic growth although having clear effects on biofilm and EPS formation. The biofilm formation and EPS production of $S$. mutans were known to be regulated by several signal transduction systems, like two-component system and second messenger signaling ${ }^{3}$. It is possible that the function of these signal systems was affected by substances in $H$. pylori supernatant. Our further research will focus on the specific mechanisms of the anti-biofilm effects of $H$. pylori supernatant.

In conclusion, our results showed the ability of $H$. pylori to destroy the balance between S. mutans and S. sanguinis in oral biofilm, creating an environment in which $S$. mutans is the dominant bacteria, promoting the formation and development of dental caries.

\section{Acknowledgements}

This study was supported by the National Natural Science Foundation of China (31200985, 81430011), and State Key Laboratory of Oral Diseases (SKLOD201414, SKLOD201609). The authors declare no conflict of interests.

\section{References}

1- Agarwal S, Jithendra KD. Presence of Helicobacter pylori in subgingival plaque of periodontitis patients with and without dyspepsia, detected by polymerase chain reaction and culture. J Indian Soc Periodontol. 2012;16(3):398-403

2- Barnabé $M$, Saraceni $C H$, Dutra-Correa $M$, Suffredini IB. The influence of Brazilian plant extracts on Streptococcus mutans biofilm. J Appl Oral Sci. 2014;22(5):366-72.

3- Cheng X, Zheng X, Zhou X, Zeng J, Ren Z, Xu X, et al. Regulation of oxidative response and extracellular polysaccharide synthesis by a diadenylate cyclase in Streptococcus mutans. Environ Microbiol. 2016;18(3):904-22 
4- Desai HG, Gill HH, Shankaran K, Metha PR, Prabhu SR. Dental plaque: a permanent reservoir of Helicobacter pylori? Scand J Gastroenterol. 1991;26(11):1205-8.

5- Dowsett SA, Kowolik MJ. Oral Helicobacter pylori, can we stomach it? Crit Rev Oral Biol Med. 2003;14(3):226-33.

6- Elsheikh MN, Mahfouz ME. Prevalence of Helicobacter pylori DNA in recurrent aphthous ulcerations in mucosa-associated lymphoid tissues of the pharynx. Arch Otolaryngol Head Neck Surg. 2005;131(9):804-8. 7- Ge Y, Caufield PW, Fisch GS, Li Y. Streptococcus mutans and Streptococcus sanguinis colonization correlated with caries experience in children. Caries Res. 2008;42(6):444-8.

8- Gebara EC, Faria CM, Pannuti C, Chehter L, Mayer MP, Lima LA. Persistence of Helicobacter pylori in the oral cavity after systemic eradication therapy. J Clin Periodontol. 2006;33(5):329-33.

9- Klein MI, Hwang G, Santos PH, Campanella OH, Koo H. Streptococcus mutans-derived extracellular matrix in cariogenic oral biofilms. Front Cell Infect Microbiol. 2015;5:10.

10- Kolho KL, Hölttä P, Alaluusua S, Lindahl H, Savilahti E, Rautelin H. Dental caries is common in Finnish children infected with Helicobacter pylori. Scand J Infect Dis. 2001;33(11):815-7.

11- Koo H, Falsetta ML, Klein MI. The exopolysaccharide matrix: a virulence determinant of cariogenic biofilm. J Dent Res. 2013;92(12):1065-73.

12- Kreth J, Giacaman RA, Raghavan R, Merritt J. The road less traveled - defining molecular commensalism with Streptococcus sanguinis. Mol Oral Microbiol. 2017;32(3):181-96.

13- Kreth J, Merritt J, Shi W, Qi F. Competition and coexistence between Streptococcus mutans and Streptococcus sanguinis in the dental biofilm. J Bacteriol. 2005;187(21):7193-203.

14- Liu P, Yue J, Han S, Deng T, Fu C, Zhu G, et al. A cross-sectional survey of dental caries, oral hygiene, and Helicobacter pylori infection in adults. Asia Pac J Public Health.2013;25(4 Suppl):49S-56S.

15- Liu $Y$, Lin H, Bai $Y$, Qin $X$, Zheng $X$, Sun $Y$, et al. Study on the relationship between Helicobacter pylori in the dental plaque and the occurrence of dental caries or oral hygiene index. Helicobacter 2008;13(4):256-60.

16- Marsh PD. Dental plaque as a microbial biofilm. Caries Res. 2004;38(3):204-11.

17- Marsh PD. Dental plaque as a biofilm and a microbial community - implications for health and disease. BMC Oral Health. 2006;6 Suppl $1: \mathrm{S} 14$.
18- Polk DB, Peek RM Jr. Helicobacter pylori: gastric cancer and beyond. Nat Rev Cancer. 2010;10(6):403-14.

19- Ren Z, Cui T, Zeng J, Chen L, Zhang W, Xu X, et al. Molecule targeting glucosyltransferase inhibits Streptococcus mutans biofilm formation and virulence. Antimicrob Agents Chemother. 2015;60(1):126-35.

20- Salama NR, Hartung ML, Müller A. Life in the human stomach: persistence strategies of the bacterial pathogen Helicobacter pylori. Nat Rev Microbiol. 2013;11(6):385-99.

21- Schmidt JC, Bux M, Filipuzzi-Jenny E, Kulik EM, Waltimo T, Weiger $R$, et al. Influence of time, toothpaste and saliva in the retention of Streptococcus mutans and Streptococcus sanguinis on different toothbrushes. J Appl Oral Sci. 2014;22(3):152-8.

22- Silva DG, Stevens RH, Macedo JM, Albano RM, Falabella ME, Veerman EC, et al. Detection of cytotoxin genotypes of Helicobacter pylori in stomach, saliva and dental plaque. Arch Oral Biol. 2009;54(7):684-8.

23- Silva JP, Castilho AL, Saraceni CH, Díaz IE, Paciencia ML, Suffredini IB. Anti-streptococcal activity of Brazilian Amazon Rain Forest plant extracts presents potential for preventive strategies against dental caries. J Appl Oral Sci. 2014;22(2):91-7.

24- Smith EG, Spatafora GA. Gene regulation in S. mutans: complex control in a complex environment. J Dent Res. 2012;91(2):133-41. 25- Smith SI, Oyedeji KS, Odeniyi OA, Arigbabu AO, Coker AO. Diagnosis of Helicobacter pylori infection among patients with dental caries by stool antigen test. $\mathrm{Br}$ J Biomed Sci. 2006;63(3):144-5. 26- Wang MY, Liu XF, Gao XZ. Helicobacter pylori virulence factors in development of gastric carcinoma. Future Microbiol. 2015;10(9):150516.

27- World Health Organization. What is the burden of oral disease? [Internet]. 2017. [cited 2017 June 22]. Available from: http://www. who.int/oral_health/disease_burden/global/en/.

28- Wroblewski LE, Peek RM Jr, Wilson KT. Helicobacter pylori and gastric cancer: factors that modulate disease risk. Clin Microbiol Rev. 2010;23(4):713-39.

29- Xiao J, Klein MI, Falsetta ML, Lu B, Delahunty CM, Yates JR 3rd, et al. The exopolysaccharide matrix modulates the interaction between 3D architecture and virulence of a mixed-species oral biofilm. PLoS Pathog. 2012;8(4):e1002623.

30- Zou QH, Li RQ. Helicobacter pylori in the oral cavity and gastric mucosa, a meta-analysis. J Oral Pathol Med. 2011;40(4):317-24. 